\title{
Effect of conditional cash transfer schemes on registration of the birth of a female child in India
}

\author{
Jenita Baruah ${ }^{1}$, Anjan Rajkonwar ${ }^{2}$, Shobhana Medhi ${ }^{3}$, Giriraj Kusre ${ }^{4}$ \\ ${ }^{1}$ Assistant Professor, Department of Community Medicine; ${ }^{4}$ Associate Professor, Department of Anatomy; Assam Medical College \\ and Hospital, Dibrugarh, India. ${ }^{2}$ Scientist-B, Regional Medical Research Centre (ICMR), Dibrugarh, India. ${ }^{3}$ Demonstrator of \\ Anatomy, Guwahati Medical College and Hospital, Guwahati, India.
}

\begin{abstract}
Girls have traditionally been neglected in India. The neglect is reflected in adverse sex ratio of 914 girls per 1000 boys as reported in 2011 census. The declining sex ratio can be prevented by the registration of female children and by ensuring their progress and safety. The study aims at finding the effect of the introduction of a conditional cash transfer scheme ('Majoni' scheme) upon the registration of a female child. It was a hospital record-based study where the preferential treatment of female children during registration into the birth register before and after the introduction of the Majoni scheme was measured. An effect of the scheme on the registration of male and female children was also compared. The introduction of this scheme increased the female to male ratio of applications for the registration of births from 1.06 to 1.34 and also increased the number of formal requests for the registration of the birth of a female child from $24.45 \%$ to $39.05 \%$. Financial incentives or securities have been shown to modify human behavior. The increase in the numbers of applications for the registration of a female child, after the introduction of the 'Majoni' scheme was due to the financial incentive attached with the registration. The increasing trend in the number of applications with every passing month was probably due to the increase in awareness regarding the benefit of the scheme. Conditional cash transfer schemes, such as Majoni, can have a significant effect on increasing the registration of female children. Further study is required to evaluate the effect of the factors other than the financial incentive upon the registration of female children.
\end{abstract}

Keywords: Conditional cash transfer, Majoni scheme, Birth registration, Female children, India.

\section{Introduction}

South Asia is the only region in the world where there is an altered sex ratio in comparison to the global standard. ${ }^{1}$ The cultural preferences for sons in many South Asian countries, and the increasing use of sex selection during pregnancy are the major causes for this alteration. ${ }^{1}$ The sex ratio, defined as the number of females per thousand males, is an important and useful indicator to assess the relative excess or deficit of men or women in a given population at that point of time. ${ }^{2}$ Sex differentials can be caused by a difference in mortality rate, migration, sex ratios at birth, and the undercounting of women at the time of population enumeration. ${ }^{3}$ Hospital records are crucial for estimating the influence of female feticide on the sex ratio, as it is not affected by factors like infanticide and neglect of female children. ${ }^{4}$

The child sex ratio in India has declined to 914 girls per 1000 boys in $2011 .{ }^{5}$ In order to improve the status of women in society, increase their chances of survival, and to reverse the distorted sex ratio, both the national and state governments in India have launched special financial incentive schemes for girls and women (also called as 'conditional cash transfer schemes' or CCTs). Dhanlakshmi scheme, Janani Suraksha Yojana, and Balika Samridhi yojana, are some of them. ${ }^{6}$ One such scheme, known as 'Majoni', was introduced in the state of Assam (India)

\section{Practice Points}

- South Asia is the only region in the world where there is an altered sex ratio in comparison to the global standard.

- Girls have traditionally been neglected in India which may be due to the payment of dowry during their marriage, or due to financial noncontribution to their family of origin after marriage.

- The 'Majoni' scheme, a conditional cash transfer scheme, has increased the awareness of the parents and guardians towards the registration of their female children.

- Conditional cash transfer schemes create incentives for households to adjust their behavior towards the protection of female children.

- Culturally relevant schemes and other strategies should be taken to improve the quality of life of girls and women in India.

Correspondence: Dr Giriraj Kusre, Associate Professor, Department of Anatomy, Assam Medical College and Hospital, DQ12, G-Lane, Assam Medical College Dibrugarh, Assam, India. E-mail: giriraj_kusre@rediffmail.com. 
on $1^{\text {st }}$ February 2009 with the aim of improving the child sex ratio. ${ }^{7,8}$ Under this scheme all girls born after this date were to get fixed deposit of Rs 5000/ into an account of the Apex Bank. ${ }^{7}$ Fixed deposits were tied to conditions of institutional delivery of the female child, the compulsory registration of the child, the adherence to the two child norm by the family, the prevention of marriage of the female child before her eighteenth birthday, giving the female child a right to en-cash the fixed deposit on her eighteenth birthday, and disallowing hypothecation of the fixed deposit till that period. ${ }^{7}$

Girls have traditionally been neglected in India. ${ }^{9}$ The analysis of 10 years of delivery records of one hospital from 1980 onwards showed that there were 44 million women missing in India. ${ }^{4}$ About 1.12 million fetuses were also found to be terminated each year due to the fetus being female. ${ }^{10}$ The preferential bias for males in the society ${ }^{11}$ creates a negative view of women resulting in the neglect of girls and women, the early death of female children ${ }^{12,13}$, antenatal sex determination, infanticide, ${ }^{11}$ and female foeticide. ${ }^{14,15}$

The findings of the census of India highlights that the sex ratio has declined gradually over the century in India, with an abrupt fall being observed after 1980, coinciding with the availability of ultrasound examinations for antenatal sex determination. As the sex ratio of children delivered in hospitals is not influenced by infanticide, the decline in sex ratio at birth was due to an increase in the feticide of female fetuses deliberately ${ }^{4}$ and after birth due to the deliberate neglect of female children. ${ }^{16}$

Registration of birth forms the first line of attack to prevent the mortality of infants as it gives them their identity $^{17}$ - about $25 \%$ of children born in India don't have an identity. ${ }^{18}$ The Registrar General of India's (RGI) data shows that the birth of 6.6 million children in India, and $27 \%$ of the births in the state of Assam went unregistered in $2007 .{ }^{18}$ The Article 7 of the UN Convention on the Rights of the Child states: 'The child shall be registered immediately after birth and shall have the right from birth to a name, the right to acquire a nationality and as far as possible the right to know and be cared for by his or her parents'. 19

Conditional cash transfer programs (CCT) gives money to poor people in return for fulfilling specific behavioral conditions. ${ }^{20}$ Financial incentives have long been used in the health sectors of low and middle income countries with the aim of achieving pre-specified performance targets related to health. A $25 \%$ decrease in the prevalence of anemia among primary school children in China and an improvement of anthropometric indicators of malnutrition by $6 \%$ in children of urban slums in India due to performance incentives paid to school principals and day care workers respectively, are some of the examples of achieving the specified targets. ${ }^{21}$

A common alternative to achieving pre-specified performance targets is to reward the use of health services and inputs, particularly those that are relatively sensitive to provider effort. Pay-for-performance incentives to health care providers in Rwanda have been able to increase institutional delivery rates by $23 \%$ and preventive service use among children under the age of 4 years by $25-50 \%{ }^{21}$ It also led to a $15 \%$ increase in the rate of HIV testing and counseling among couples, and an $18 \%$ increase in the probability that both partners in HIV discordant households had been tested for HIV at least once. $^{21}$

Payments, as conditional cash transfers, are made for using prevention services and achieving educational targets, and are believed to improve health outcomes. ${ }^{22}$ Financial incentives attached to the Majoni scheme were aimed at ensuring the birth registration of female children and thereby increase their chances of survival. The present study attempts to assess the effect of financial incentives on the application pattern for the certificate of registration of birth of a female child in the State of Assam, India.

\section{Materials and methods}

The study was conducted in a tertiary care health centre situated in the eastern part of India (State of Assam), where about 6000 to 7000 births take place per year in the Obstetrics and Gynaecology Department. These children are registered and the Medical Record Department (MRD) of the centre maintains the records of the date of birth, sex of the newborn, names of the parents, date of receipt of the formal request for the certificate of registration of birth, and date certificates were given. Although all children born in the centre are registered, a certificate of registration of birth is awarded to the parents of the child only after receiving a formal request from them.

The data was obtained through a hospital record-based cross-sectional study over a period of 2 years (February 2008 -January 2010). Records were assessed by the investigators from Medical Record Department. A formal permission from the Hospital Superintendent for the collection of the data was taken. To maintain confidentiality, no data pertaining to the identity of the patients (such as name and address) were recorded.

The demographic records of infants, along with records of applications requesting a certificate for children born both before and after the implementation of the 'Majoni' scheme were collected. Records of only those children whose applications were received within one month of the birth of the child (legal time limit - 21 days) were analysed.

The female to male $(\mathrm{F} / \mathrm{M})$ ratio of applications for the certificate and the trend of applications for the certificate of registration of girls were compared for children born before and after the implementation of the 'Majoni' scheme. Student's 't' test using SPSS Version 21 was done to test the significance of the difference. 


\section{Results}

A total of 6345 children were born during the period of Feb 2008 to Jan 2009 and 6823 children were born between Feb 2009 and Jan 2010 (Table 1). There was no significant difference between numbers of girls and boys born before and after the implementation of the scheme; 911 and 924 females per 1000 boys born before and after the implementation of scheme respectively.

The implementation of the 'Majoni' scheme increased the average female to male ratio (F/M) of applications for the registration of births from 1.06 to 1.34 (Table 1) (Fig 1) and also increased the number of formal requests made for a certificate of registration of birth for a female child from $24.45 \%$ to $39.05 \%$ (Table 1) (Fig 2). The increase in the number of applications made for female children after implementation was significantly more $(\mathrm{p}<0.000)$.

\section{Discussion}

The average national sex ratio at birth (SRB) in humans is slightly male biased (105 males per 100 females), ${ }^{23}$ and this was also observed in the present case where there were found to be 109.6 and 108.1 male births per 100 female births during the first and the second years of the study period, respectively. The sex ratios in the pre and post implementation years were comparable denoting that the sex ratio was independent of any financial incentives and that the difference in numbers of the registration at birth of female children was not due to any change of the sex ratio at birth.

Girls, in many parts of India, have traditionally been seen as an economic liability due to the payment of dowry during their marriage, or due to financial noncontribution to their family of origin after marriage. ${ }^{24} \mathrm{~A}$ Tamil proverb says: 'Having a daughter is like watering a flower in the neighbour's garden'. ${ }^{11}$ There has been a deliberate neglect of girls, sometimes leading to their early death. ${ }^{12,13}$ The financial burden has been a strong factor for the needs of children. ${ }^{25}$ A reduction of the financial burden on the family of a female child can reduce this deliberate neglect. Changing the status of women from being an economic liability to an asset can bring around a change in this situation. ${ }^{26}$

Financial incentives or securities have been shown to modify human behaviour in various situations. Conditional cash transfer programmes (CCT) give money to poor people in return for fulfilling specific behavioural conditions. ${ }^{20}$ Conditional cash transfers were first started in the Latin American countries of Mexico, Brazil, Colombia, Honduras, and Nicaragua. ${ }^{20} \mathrm{CCT}$ s were also implemented or were discussed in other middle and low income countries, such as Bangladesh, Kenya,

Table 1: Applications for issue of certificate of birth registration before and after implementation of the Majoni scheme

\begin{tabular}{|c|c|c|c|c|c|c|c|}
\hline $\begin{array}{c}\text { Month/ } \\
\text { year }\end{array}$ & $\begin{array}{c}\text { Total } \\
\text { Male } \\
\text { children }\end{array}$ & $\begin{array}{l}\text { Application } \\
\text { received for } \\
\text { male children }\end{array}$ & $\begin{array}{l}\text { Application re- } \\
\text { ceived for male } \\
\text { children }(\%)\end{array}$ & $\begin{array}{c}\text { Total } \\
\text { female } \\
\text { children }\end{array}$ & $\begin{array}{c}\text { Application } \\
\text { received for } \\
\text { female children }\end{array}$ & $\begin{array}{l}\text { Applications re- } \\
\text { ceived for female } \\
\text { children }(\%)\end{array}$ & $\begin{array}{l}\text { F/M } \\
\text { ratio }\end{array}$ \\
\hline Feb 08 & 235 & 62 & 26.38 & 241 & 58 & 24.06 & 0.912 \\
\hline Mar 08 & 292 & 61 & 20.89 & 233 & 58 & 24.89 & 1.19 \\
\hline Apr 08 & 214 & 53 & 24.76 & 209 & 50 & 23.92 & 0.96 \\
\hline May 08 & 227 & 50 & 22.02 & 188 & 38 & 20.21 & 0.91 \\
\hline June 08 & 218 & 47 & 21.55 & 208 & 45 & 21.63 & 1 \\
\hline July 08 & 277 & 60 & 21.66 & 241 & 64 & 26.55 & 1.22 \\
\hline Aug 08 & 335 & 91 & 27.16 & 297 & 74 & 24.91 & 0.91 \\
\hline Sept 08 & 299 & 60 & 20.06 & 300 & 61 & 20.33 & 1.01 \\
\hline Oct 08 & 314 & 76 & 24.2 & 292 & 89 & 30.47 & 1.25 \\
\hline Nov 08 & 283 & 50 & 17.66 & 236 & 50 & 21.18 & 1.19 \\
\hline Dec 08 & 292 & 64 & 21.91 & 285 & 88 & 30.87 & 1.4 \\
\hline \multirow[t]{2}{*}{ Jan 09} & 333 & 94 & 28.22 & 296 & 72 & 24.32 & 0.86 \\
\hline & & \multicolumn{4}{|r|}{ Average } & 24.45 & 1.06 \\
\hline \multicolumn{8}{|c|}{ Majoni Scheme implemented } \\
\hline Feb 09 & 266 & 64 & 24.06 & 267 & 73 & 27.34 & 1.13 \\
\hline Mar 09 & 321 & 79 & 24.61 & 307 & 102 & 33.22 & 1.34 \\
\hline Apr 09 & 286 & 85 & 29.72 & 227 & 74 & 32.59 & 1.09 \\
\hline May 09 & 259 & 89 & 34.36 & 232 & 100 & 43.1 & 1.25 \\
\hline June 09 & 231 & 80 & 34.63 & 202 & 87 & 43.06 & 1.24 \\
\hline July 09 & 299 & 80 & 26.75 & 266 & 117 & 43.98 & 1.64 \\
\hline Aug 09 & 304 & 86 & 28.28 & 272 & 109 & 40.07 & 1.41 \\
\hline Sept 09 & 339 & 74 & 21.82 & 326 & 125 & 38.34 & 1.75 \\
\hline Oct 09 & 327 & 92 & 28.13 & 326 & 136 & 41.71 & 1.48 \\
\hline Nov 09 & 277 & 87 & 31.4 & 287 & 116 & 40.41 & 1.28 \\
\hline Dec 09 & 321 & 117 & 36.44 & 274 & 116 & 42.33 & 1.16 \\
\hline \multirow[t]{2}{*}{ Jan 10} & 315 & 100 & 31.74 & 292 & 124 & 42.46 & 1.33 \\
\hline & & \multicolumn{4}{|r|}{ Average } & 39.05 & 1.34 \\
\hline
\end{tabular}




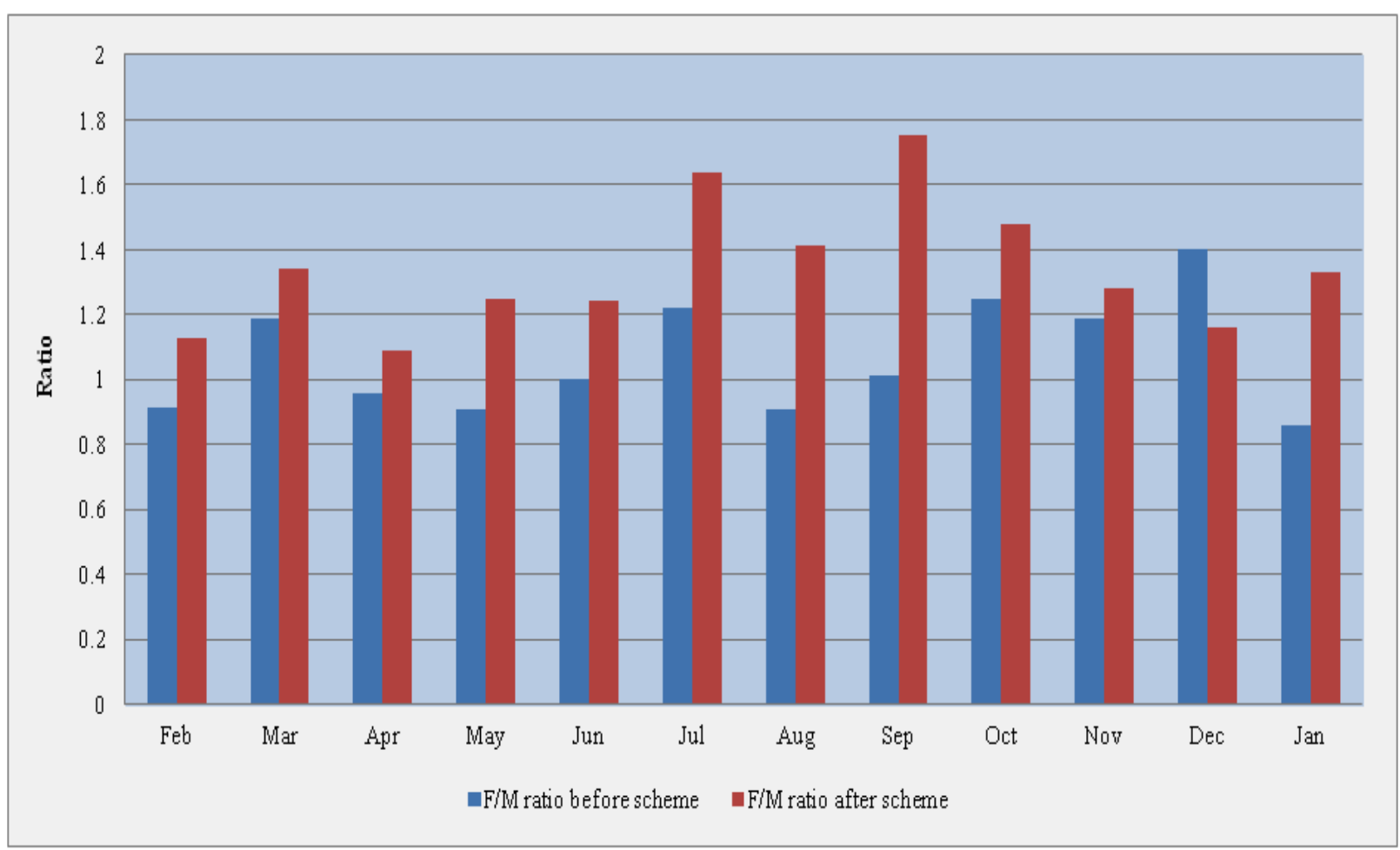

Figure 1: Female to male ratio of applications before and after implementation of Majoni scheme

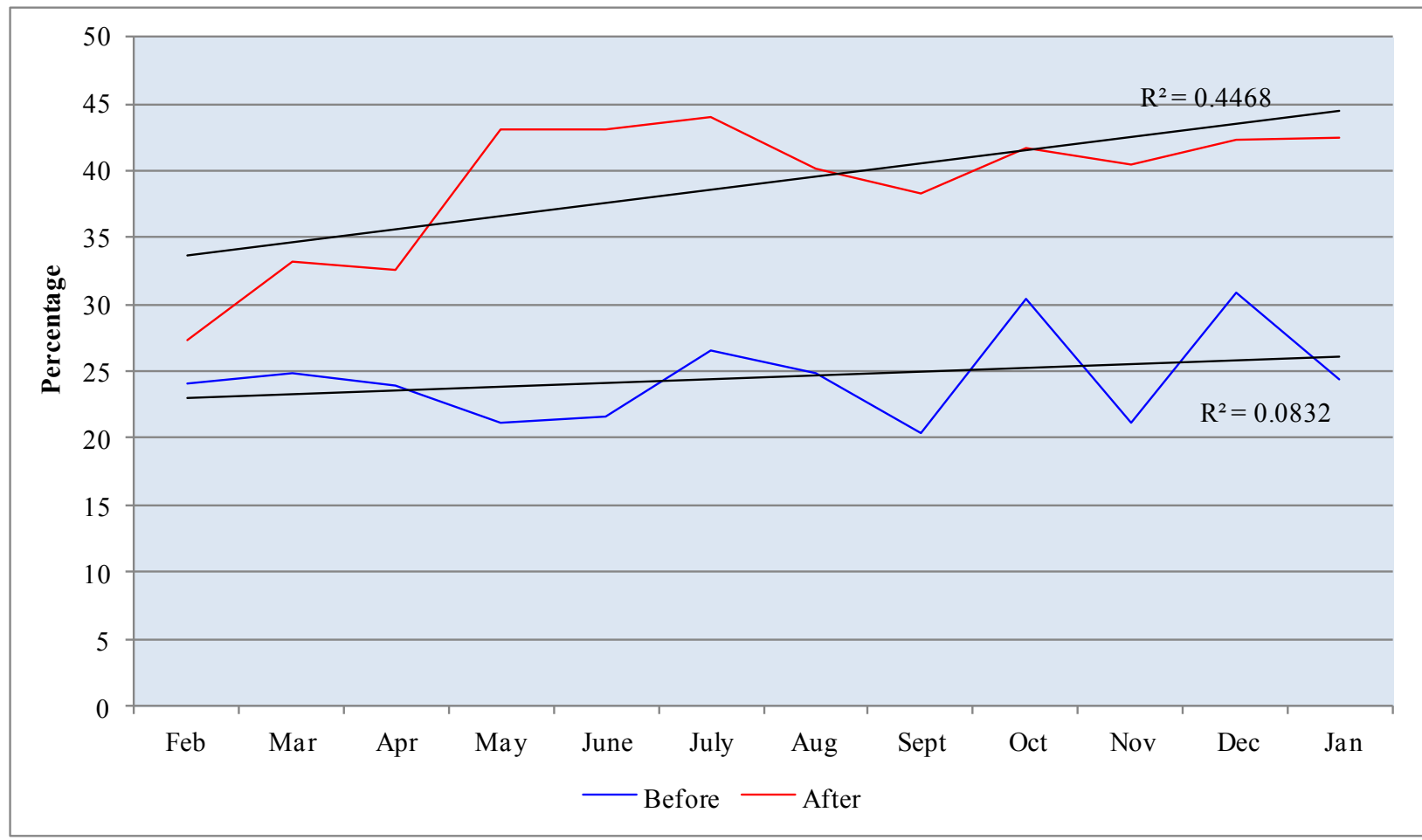

Figure 2: Trends of applications received for female children before and after implementation of the Majoni scheme

Cambodia, Turkey, South Africa, Indonesia and Côte d'Ivoire. ${ }^{20}$ Evaluation results from the first generation of CCTs from Columbia, Mexico, and Nicaragua have shown that CCTs were successful in increasing school enrolment rates, improving preventive health care, and raising household food consumption. ${ }^{27}$ In India, schemes with CCTs, such as the Janani Suraksha Yojana, have successfully achieved their aims of increasing institutional delivery. ${ }^{28}$ The Majoni scheme was a conditional cash incentive scheme providing financial incentive-based social security, ensuring the registration of female children, periodic check-ups for their progress and safety, and the prevention of early marriage. ${ }^{7}$ The present study shows that the provision of financial incentives for the registration of a female child under the Majoni Scheme has increased the preferential treatment of female children. This preferential treatment is indicated by an increase in the numbers of formal requests 
by parents to get a certificate of registration of birth of a female child and by the significant improvement in female to male ratio of applications.

Raising awareness about health programmes increases the acceptability of the programme among the population. ${ }^{29}$ An increasing trend in the percentage of applications with every passing month was probably due to an increase in awareness of the benefits of the scheme (Fig 2).

The study period included only the first year of the implementation of the scheme. Even though the time frame of the study is too short to comment on the success of the 'Majoni' scheme, the scheme has shown a positive effect on the registration of births of the female children. The evidence reveals that conditional cash transfer schemes can help in improving the numbers of female births that are registered in India.

The study has also a number of limitations. The study was limited to the year prior to implementation and the year just after the implementation of the scheme. The duration of the study is too short to comment on the long term benefits of the scheme. Other factors associated with the registration of female children were not studied.

\section{Conclusion}

The present study shows that the introduction of a conditional cash transfer scheme (the 'Majoni' scheme) increased the numbers of formal applications for the registration of female children. Such a scheme can prevent the alteration of the child sex ratio and can improve the health status of female children. Further study needs to be carried out to review the long term impact of the programme and its benefits to female children. Culturally relevant schemes and other strategies should be taken to improve the quality of life of girls and women in India.

\section{Acknowledgement}

We acknowledge the support of the Department of Medical Records, Assam Medical College and Hospital, Dibrugarh, Assam, India, for allowing the access of the data. We also acknowledge the support of Mr Vinay Kumar Rai and Mr Pranab Gogoi in analysing data.

\section{References}

1. UNICEF. The State of South Asia's Children 2005. Kathmandu: United Nations Children's Fund (UNICEF), Regional Office for South Asia, 2004.

2. Census of India 2011. Gender composition. http://censusindia.gov.in/Census And You/ gender composition.aspx (accessed on June 2013)

3. Census of India 2011. Census of India 2001: Provisional population totals; Chapter 6, census of India. http://censusindia.gov.in./Data Product/ Library/provisional_population_total_link/PDFlink/chpater6.pdf (accessed on June 2013)

4. Sahni M, Verma N, Narula D , Varghese RM, Sreenivas V, Puliyel JM. Missing Girls in India: Infanticide, Feticide and Made-to- Order Pregnancies? Insights from Hospital-Based Sex- Ratio-at-Birth over the Last Century. PLoS ONE 2008;3(5): e2224.

5. Census of India 2011. Census of India: Child sex ratio(0-6years) among the population . http:// www.censusindia.gov.in/2011-prov-results/ data files/india/Final PPT 2011 chapter5.pdf (accessed on June 2013)

6. Prabhu KS, Sahay R, Roy R, and Vinay C. Conditional Cash transfer Schemes for alleviating human Poverty: Relevance for India. UNDP India, 2009.

7. Government of Assam. Majoni Guideline. http:// w w w. nrhmass a m.in/pdf/guidelin e/ majoni_guidelines.pdf (accessed on June 2013)

8. Government of Assam. Chief Minister's vision for women and children 2016; Planning and development department. http:// o n l i n e.a s s a m.g o v. i n / documents/218378/12d52615-5f98-4f95-860d557aab61d779 (accessed on June 2013)

9. CSSS. Status of Women in India: Problems and Concerns, Internship Project. Mumbai: Centre For study Of Society and Secularism, 2011.

10. Seth S. Sex selective feticide in India. J Assist Reprod Genet 2007;24:153-4.

11. Sekher TV, Hatti N. Disappearing Daughters and Intensification of Gender Bias: Evidence from Two Village Studies in South India. Sociol Bull 2010;59:111-33.

12. The Million Death Study Collaborators. Causes of neonatal and child mortality in India: a nationally representative mortality survey. Lancet 2010;376:1853-60.

13. Khanna R, Kumar A, Vaghela JF, Sreenivas V, Puliyel JM. Community based retrospective study of sex in infant mortality in India. $B M J$ 2003;327:126-30.

14. Ministry of Statistics and Programme implementation. Government of India. Children in India 2012- A statistical appraisal. http://mospi.nic.in/ mospi_new/upload/Children in_India_2012.pdf (accessed on June 2013)

15. Jha P, Kesler MA. Trends in selective abortion of female foetuses in India: analysis of nationally representative birth histories from 1990-2005 and census data from 1991-2011. Lancet 2011;377(9781):1921-8. 
16. Tripathy SN, Pradhan S. Girl child in India. New Delhi: Discovery Publishing House, 2003.

17. Wilbur CL. Needs and present status of birth registration. J Natll Med Assoc 1915;7:121-5.

18. Sinha K. $25 \%$ Indian births not registered. Times of India. 2 March 2012. http:// articles.timesofindia.indiatimes.com/2012-03-02/ india/31116505 1 registration-indian-statesdeath (accessed on June 2013)

19. UNICEF. UN Convention on the Rights of the Child. London: UNICEF, 1989.

20. Doetinchem O, Xu K, Carrin G. Conditional cash transfer: What's in it for health? Technical Briefs for Policy Makers, Number 1. Department of Health Financing, Health Financing Policy. Geneva: World Health Organization, 2008.

21. Miller G, Babiarz K S. Pay-for-performance incentives in low- and middle-income country health programs. Cambridge: National Bureau of Economic Research, 2013.

22. Prabhu KS, Sahay R, Roy R, Vinay C. Conditional Cash transfer Schemes for alleviating human Poverty: Relevance for India. New Delhi: UNDP, 2009.
23. Dama MS. Sex Ratio at Birth and Mortality Rates Are Negatively Related in Humans. PLoS ONE 2011;6: e23792.

24. Abeykoon ATPL. Sex Preference in South Asia: Sri Lanka an Outlier. Asia-Pacific Popul J 1995;10:5-16.

25. Newacheck PW, Hughes DC, Hung YY, Wong S and Stoddard JJ. The Unmet Health Needs of America's Children. Paediatrics 2000;105:989.

26. The CPC Livelihoods and Economic Strengthening Task Force. Children and Economic Strengthening Programs: Maximizing Benefits and Minimizing Harm. Washington, DC: USAID, 2013.

27. Rawlings LB, Rubio GM. Evaluating the Impact of Conditional Cash Transfer Programs. World Bank Res Obser 2005;20:29-55

28. Lim SS, Dandona L, Hoisington JA, James SL, Hogan MC, Galidou E. India's Janani Suraksha Yojana: A condition cash transfer program to increase births in health facilities; An impact evaluation. Lancet 2010; 375:2009-23.

29. Do YK, Wong KY. Awareness and acceptability of human papillomavirus vaccine: an application of the instrumental variables bivariate probit model. BMC Public Health 2012;12:31. 